\title{
A cleaner application on hydrogen sulfide
}

\author{
Merve Aksu, Mehmet Hakan Morcali*
}

Gaziantep University, Naci Topcuoglu Vocational High School, Gaziantep, Turkey, merveaks1996@gmail.com, ORCID: 0000-0003-1212-8060, hakanmorcali@gmail.com, ORCID: 0000-0002-5021-4459.

\begin{abstract}
A B S T R A C T
With the increasing industrial production, there was a significant number of toxic and harmful hydrogen sulfide $\left(\mathrm{H}_{2} \mathrm{~S}\right)$ gas generated. Due to the industrial activities, converting $\mathrm{H}_{2} \mathrm{~S}$ gas from the waste of industrial process is environmentally attractive. This paper focuses on the conversion of $\mathrm{H}_{2} \mathrm{~S}$ to elemental sulfur $\left(\mathrm{S}^{\circ}\right)$ and other sulfur species (i.e., sulfite ion $\left(\mathrm{SO}_{3}{ }^{2-}\right)$; sulfate ion $\left(\mathrm{SO}_{4}{ }^{2-}\right)$ using Fenton reagent. The effects of some reaction parameters such as $\mathrm{Fe}^{2+}$ ion concentration, amount of hydrogen peroxide $\left(\mathrm{H}_{2} \mathrm{O}_{2}\right)$, reaction time, initial $\mathrm{H}_{2} \mathrm{~S}$ concentration and, liquid-gas ratio on $\mathrm{H}_{2} \mathrm{~S}$ conversion percentage were explored thoroughly. The results revealed that the increase of the $\mathrm{Fe}^{2+}$ ion concentration and $\mathrm{H}_{2} \mathrm{O}_{2}$ quantity could promote the conversion of $\mathrm{H}_{2} \mathrm{~S}$. Besides, the comparable results were recorded for each reaction parameter. An apparent positive effect was observed with increasing the amount of $\mathrm{H}_{2} \mathrm{O}_{2}$ on $\mathrm{H}_{2} \mathrm{~S}$ conversion. However, the conversion percentage was decreased while increased in the initial concentration of the $\mathrm{H}_{2} \mathrm{~S}$ in the Fenton reactor. It was well accepted that the main conversion pathway of $\mathrm{H}_{2} \mathrm{~S}$ was hydroxyl radical $(\bullet \mathrm{OH})$. Additionally, the oxidative reaction of $\mathrm{H}_{2} \mathrm{O}_{2}$ on $\mathrm{H}_{2} \mathrm{~S}$ is thought another removal pathway. The expected products are sulphuric acid and $\mathrm{S}^{\circ}$.
\end{abstract}

\section{ART I CLE INFO}

\section{Research article}

Received: 16.06.2021

Accepted: 15.10 .2021

Keywords:

conversion,

hydrogen sulfide,

fenton reagent,

hydroxyl radical $(\bullet \mathrm{OH})$

${ }^{*}$ Corresponding author

\section{Introduction}

Hydrogen sulfide $\left(\mathrm{H}_{2} \mathrm{~S}\right)$ is highly toxic, poisonous, corrosive, and, flammable. It is also with the characteristic foul odor of rotten eggs. $\mathrm{H}_{2} \mathrm{~S}$ commonly occurs in oil-gas production, volcanic gases, natural gas, coal/biomass gasification, leaching of sulfide-based ores, wastewater treatment, etc [13]. Acid rain, also called acid deposition, can easily occur in the polluted air when $\mathrm{H}_{2} \mathrm{~S}$ is oxidized to sulfur dioxide $\left(\mathrm{SO}_{2}\right)$ [2]. Besides, it affects nearly everything. Nowadays, various industrial companies have focused on eliminating $\mathrm{H}_{2} \mathrm{~S}$ due to the implementation of more strict environmental rules by the governments and also having bad odorous and occurring corrosive conditions in the production areas. However, most of them do not have still a plan regarding the $\mathrm{H}_{2} \mathrm{~S}$ removal process. Until recently, various technologies have been investigated for removing $\mathrm{H}_{2} \mathrm{~S} \quad[1,2,4,5] . \quad \mathrm{H}_{2} \mathrm{~S}$ removal technologies can be collected in two main groups. These are physicochemical methods and biotechnological methods. The physicochemical method generally contains ozonation, photo/catalytic/chemical oxidation, photo-decomposition, several absorption techniques, etc. $[1,3,6,9]$. The biotechnological method primarily comprises biochemical processes such as thiobacillus sp., thermothrix azorensis, and thiothrix nivea, thioalkalispira microaerophila, cholorobium limicola [10-13]. In these processes, the conversion of $\mathrm{H}_{2} \mathrm{~S}$ and other sulfur compounds has been widely provided by a bacterium. The $\mathrm{H}_{2} \mathrm{~S}$ conversion efficiency of these methods shows promising results in some respects, but some problems still have been observed. These processes require high investment costs and equipment corrosion occurs during the process. Therefore, developing a new process and/or update the $\mathrm{H}_{2} \mathrm{~S}$ removal process is an important study area for scientists. Nowadays, the Fenton process is mainly preferred to remove and/or oxidize more organic/inorganic compounds in wastewater with generating powerful hydroxyl radicals $(\bullet \mathrm{OH})$ from that process $[14,15]$. Due to several advantages such as strong oxidizing ability, simple process, and no secondary pollution, it has already started to apply wastewater treatment and also gas purification. The accepted possible reaction route of the Fenton process is following the formation of the hydroxyl radical. It was summarized in equation $1[10,14]$.

$$
\mathrm{Fe}^{2+}+\mathrm{H}_{2} \mathrm{O}_{2} \longrightarrow \mathrm{Fe}^{3+}+\cdot \mathrm{OH}+\mathrm{OH}^{-}
$$

In this reaction, the ferrous ions (i.e.,Fe(II)) oxidized to ferric ion (i.e., $\mathrm{Fe}(\mathrm{III})$ ) and, the hydroxyl radical (i.e., $\left.{ }^{\bullet} \mathrm{OH}\right)$ was produced. It is a strong oxidizer and, also the redox potential is $2.80 \mathrm{~V}$. Several studies have been carried out regarding the removal of sulfur compounds from different kinds of waste sources with the Fenton reagent. For instance, the removal of 
nitrogen monoxide (NO) from flue gas using the Fenton process has been studied [16]. A similar experimental setup was carried out [17] to remove $\mathrm{SO}_{2}$ and $\mathrm{NO}$ from flue gas. According to the published articles, the possible reaction's mechanism between $\mathrm{H}_{2} \mathrm{~S}$ and $\bullet \mathrm{OH}$ can be summarized in the following reactions:

$$
\begin{aligned}
& \mathrm{H}_{2} \mathrm{~S}+\cdot \cdot \mathrm{OH} \rightarrow \mathrm{HS} \cdot+\mathrm{H}_{2} \mathrm{O} \\
& \mathrm{HS} \cdot \bullet \cdot \cdot \mathrm{OH} \rightarrow \mathrm{S}^{\circ} \downarrow+\mathrm{H}_{2} \mathrm{O} \\
& \mathrm{HS}^{-}+\cdot \mathrm{OH} \rightarrow \mathrm{HSOH}^{-} \\
& \mathrm{HSOH}^{-}+\mathrm{H}_{2} \mathrm{O}_{2} \rightarrow \mathrm{H}_{2} \mathrm{SO}_{3}+\mathrm{H}_{2} \\
& \mathrm{H}_{2} \mathrm{SO}_{3}+\cdot \mathrm{OH}_{2} \rightarrow \mathrm{H}_{2} \mathrm{SO}_{4}+\cdot \mathrm{H} \\
& \mathrm{H}_{2} \mathrm{SO}_{3}+\mathrm{H}_{2} \mathrm{O}_{2} \rightarrow \mathrm{H}_{2} \mathrm{SO}_{4}+\mathrm{H}_{2} \mathrm{O}
\end{aligned}
$$

Recently, amine-based solution has been studied to remove $\mathrm{H}_{2} \mathrm{~S}[2,5,18,19]$ and also the Fenton process has been the most widely investigated by researchers. The results of the Fenton process encouraged the authors to investigate the Fenton reagent on $\mathrm{H}_{2} \mathrm{~S}$ gas. Furthermore, some studies have been extensively published in this field. The removal of $\mathrm{H}_{2} \mathrm{~S}$ gas was investigated [4], who examined the conversion of $\mathrm{H}_{2} \mathrm{~S}$ from generating coal mining area. Another interesting study was published [20], who studied the conversion of $\mathrm{H}_{2} \mathrm{~S}$ in the presence of $\mathrm{UV}$ radiation as a catalyst in order to remove of $\mathrm{H}_{2} \mathrm{~S}$. However, the studies related to remove $\mathrm{H}_{2} \mathrm{~S}$ from the gas phase using the Fenton process are very scarce.

The goal of this study was to establish facile methods for producing elemental sulfur and to determine the reaction parameters for the Fenton process. The determination of the Fenton process parameters is significant for the conversion reaction. The precipitated solid characterization showed that the elemental sulfur was found as a significant compound in the conversion of $\mathrm{H}_{2} \mathrm{~S}$ by the Fenton process. These results presented that the Fenton process can be applied for pollution control, and sustainable products are quickly recovered from wastewater for a circular economy prospect. By reusing the products for different chemical processes, the concentration of sulfuric acid could be increased. It is possible to increase the sulfuric acid concentration to the industrial usage such as: accumulator industry, fertilizers, and plasterboard industry [1-4]. The Fenton process has been applied in the chemical process for a long time and will undoubtedly play a prominent role in the future. As demonstrated, the Fenton reagent can convert the $\mathrm{H}_{2} \mathrm{~S}$ efficiently.

\section{Materials and methods}

All experiments were carried out in a $250 \mathrm{~mL}$ three-neck borosilicate-tempered glass reactor and three washing bottle reactors $(12 \mathrm{~cm}$ internal diameter; $45 \mathrm{~cm}$ length; Glass; spraying height is about $20 \mathrm{~cm}$ ). There are two bottle reactors were used to convert $\mathrm{H}_{2} \mathrm{~S}$ to sulfur compounds and, the last one was used to the measure concentration of the remaining gas (i.e., rest of $\mathrm{H}_{2} \mathrm{~S}$ ). The $\mathrm{H}_{2} \mathrm{~S}$ gas was purged with a carrier gas $\left(\mathrm{N}_{2}\right)$ into the reactor. The mixture of gas $\left(\mathrm{H}_{2} \mathrm{~S}+\mathrm{N}_{2}\right)$ was continuously purged into the reactor via a plastic pipe from a compressed gas cylinder. A $0.1 \mathrm{~L} / \mathrm{min}$ of stripping gas that contained $\mathrm{H}_{2} \mathrm{~S}$ was measured by using the flow meter. The schematic image of the experimental setup was described in Fig. 1.

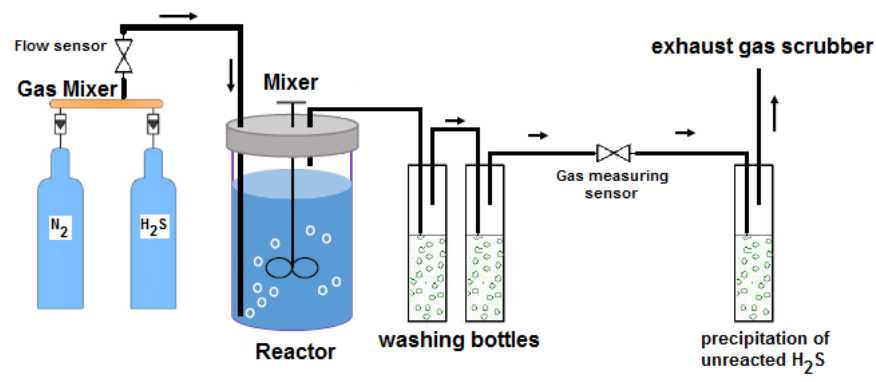

Figure 1. Experimental process of the conversion of $\mathrm{H}_{2} \mathrm{~S}$

All chemicals were analytical grade, and also all experiments were carried out using deionized water unless otherwise stated. $400 \mathrm{~mL}$ of Fenton reagent $\left(\mathrm{Fe}^{2+} / \mathrm{H}_{2} \mathrm{O}_{2}\right)$ was prepared using $\mathrm{H}_{2} \mathrm{O}_{2}$ and $\mathrm{FeCl}_{2}$ solution. The solution was divided into two washing bottles. The $\mathrm{pH}$ of the Fenton reagent solution was measured and, if necessary, set to the desired value by the $\mathrm{HCl}$ and the $\mathrm{NaOH}$ before adding the Fenton reagent into the washing bottle reactors. The temperature of the solutions was kept constant in the whole experiment. The mixture of gases (i.e., containing- $\mathrm{H}_{2} \mathrm{~S}$ and $\mathrm{N}_{2}$ ) directly purged into the reactor and the solution was continuously stirred with a magnet to provide a gas-liquid reaction. The exhaust (i.e., unreacted gas) concentration of $\mathrm{H}_{2} \mathrm{~S}$ was measured by antimony potassium tartrate $\left(\mathrm{K}_{2} \mathrm{Sb}_{2}\left(\mathrm{C}_{4} \mathrm{H}_{2} \mathrm{O}_{6}\right)_{2}\right)$ solution. All experiment running time was kept for $60 \mathrm{~min}$. The unreacted $\mathrm{H}_{2} \mathrm{~S}$ gas in the exhaust gas subsequently was precipitated as antimony tri sulfur $\left(\mathrm{Sb}_{2} \mathrm{~S}_{3}\right)$ for further purification. After completing the $\mathrm{H}_{2} \mathrm{~S}$ conversion process, the solution was filtrated and washed acetone to obtain dry powder. The weight of powder was recorded and then validated by XRD and SEM-EDX techniques which can reference the literature $[9,13]$. Afterward, the possible ions (i.e., $\mathrm{SO}_{3}{ }^{2-}$ and $\mathrm{SO}_{4}{ }^{2-}$ ) were determined by using ion chromatography (IC) (Perkin Elmer IC1000). The conversion of $\mathrm{H}_{2} \mathrm{~S}$ is calculated by the following Eq. (8):

$$
\mathrm{H}_{2} \mathrm{~S} \text { conversion, } \%=\left[\left(\mathrm{C}_{\text {in }}-\mathrm{C}_{\text {out }}\right) / \mathrm{C}_{\text {in }}\right] \times 100
$$

Where; $\mathrm{C}_{\text {in }}$ is inital concentration of $\mathrm{H}_{2} \mathrm{~S}$, ppm; $\mathrm{C}_{\text {out }}$ is $\mathrm{H}_{2} \mathrm{~S}$ concentration in exhaust gas, ppm.

\section{Results and discussions}

\subsection{Effects of $\mathrm{Fe}^{2+}$ concentration on $\mathrm{H}_{2} \mathrm{~S}$ conversion}

The effect of ferrous ion $\left(\mathrm{Fe}^{2+}\right)$ concentration on $\mathrm{H}_{2} \mathrm{~S}$ conversion was investigated. In this experimental study, 1000 ppm $\mathrm{H}_{2} \mathrm{~S}$ gas was continuously fed into the Fenton reactor containing $600 \mu \mathrm{L}$ of $\mathrm{H}_{2} \mathrm{O}_{2}(30 \%)$ at $400 \mathrm{rpm}$ for $60 \mathrm{~min}$ at $25^{\circ} \mathrm{C}$. The $\mathrm{H}_{2} \mathrm{~S}$ conversion percentage and also distribution of 
sulfur compound percentage results were demonstrated in Figure 2. Without Fenton reaction, the $\mathrm{H}_{2} \mathrm{~S}$ conversion percentage was recorded at $8.9 \%$ via $\mathrm{H}_{2} \mathrm{O}_{2}$. The direct oxidation of $\mathrm{H}_{2} \mathrm{~S}$ with $\mathrm{H}_{2} \mathrm{O}_{2}$ and $\bullet \mathrm{OH}$ radical can be expressed by the following reactions [4]:

$$
\begin{aligned}
\mathrm{H}_{2} \mathrm{~S}+\mathrm{H}_{2} \mathrm{O}_{2} & \rightarrow 2 \mathrm{H}_{2} \mathrm{O}+\mathrm{S}^{\circ} \downarrow \\
\mathrm{HS} \bullet+\bullet & \mathrm{OH} \rightarrow \mathrm{S}^{\circ} \downarrow+\mathrm{H}_{2} \mathrm{O}
\end{aligned}
$$

$\mathrm{H}_{2} \mathrm{~S}$ conversion percentage consistently increased with increasing ferrous ion concentration in the range of 12.5-125 $\mathrm{mM}$, as expected since the reaction was canalized to the right side with increasing ferrous ion concentration (see Eq.1). A similar experiment was carried out in the literature [21]. They found that ferrous ion has a positive effect on $\mathrm{H}_{2} \mathrm{~S}$ conversion. The conversion of $\mathrm{H}_{2} \mathrm{~S}$ percentage, however, was leveled off with further ferrous ion elevated. The results exhibited that the concentration of ferrous ion was increased while $\mathrm{H}_{2} \mathrm{~S}$ conversion percentage increased rapidly from around 30 to $80 \%$.

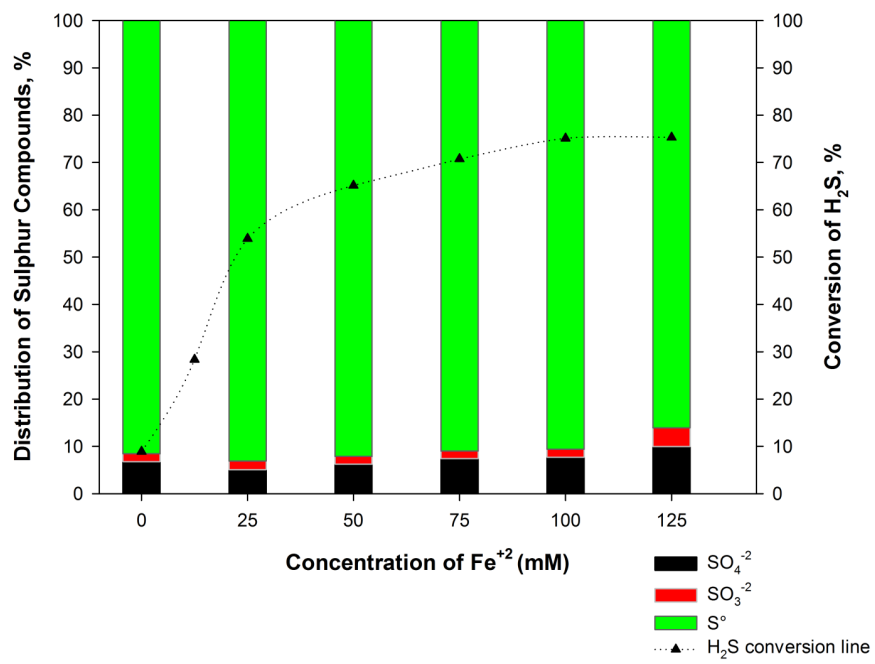

Figure 2. Changes of $\mathrm{H}_{2} \mathrm{~S}$ conversion percentage versus $\mathrm{Fe}^{+2}$ ion concentration

To understand the distribution of sulfur compounds (i.e., $\mathrm{S}^{\circ}$, $\mathrm{SO}_{3}{ }^{2-}, \mathrm{SO}_{4}{ }^{2-}$ ), they were determined using spectrometric methods, explained in the experimental section before. The results demonstrated that the small part of elemental sulfur could be directly oxidized by free $\mathrm{H}_{2} \mathrm{O}_{2}$. Interestingly, the sulfate ion $\left(\mathrm{SO}_{4}{ }^{2-}\right)$ concentration was moderately increased when increasing $\mathrm{Fe}^{2+}$ concentration. When compared with the sulfite ion $\left(\mathrm{SO}_{3}{ }^{2-}\right)$ concentration which was not regularly increased.

This result was supported via a chemical reaction between $\mathrm{H}_{2} \mathrm{O}_{2}$ and $\mathrm{Fe}^{2+}$. Finally, the radical $\bullet \mathrm{OH}$ can be produced in the solution. The possible reaction pathway is summarized in the introduction section (see Eq.1). According to this equation, the reaction was occurred between $\mathrm{H}_{2} \mathrm{O}_{2}$ and $\mathrm{Fe}^{2+}$ and also to produce $\cdot \mathrm{OH}$ free radical. This reaction can be prompted to the right side with increasing of $\mathrm{Fe}^{2+}$ concentration. In this way, the yield of $\cdot \mathrm{OH}$ radical can increase in solution and enhancing $\mathrm{H}_{2} \mathrm{~S}$ conversion percentage. However, more ferrous ion concentration consumes the radical $\bullet \mathrm{OH}$ in the solution since it has a very high reaction rate given in Eq.11 [21].

$$
\mathrm{Fe}^{2+}+\cdot \mathrm{OH} \rightarrow \mathrm{Fe}^{3+}+\mathrm{OH}^{-} \quad \mathrm{k}=3.0 \times 10^{8} \mathrm{M}^{-1} \mathrm{~s}^{-1}
$$

Due to this restriction, more $\mathrm{Fe}^{2+}$ ions cannot further provide an extensive conversion of the percentage of $\mathrm{H}_{2} \mathrm{~S}$. The results showed that the Fenton process produced three sulfur species $\left(\mathrm{S}^{\circ}, \mathrm{SO}_{3}{ }^{2-}, \mathrm{SO}_{4}{ }^{2-}\right.$ ) from the $\mathrm{H}_{2} \mathrm{~S}$ by oxidation potential of $\bullet \mathrm{OH}$ radical and also $\mathrm{H}_{2} \mathrm{O}_{2}$ (see Eqs. 2-7). Based on the results, the conversion process includes two process stages: first producing $\cdot \mathrm{OH}$ radicals to oxidize $\mathrm{H}_{2} \mathrm{~S}$ molecules, and second, determination of the type of sulfur compounds and recovery followed by $\mathrm{S}^{\circ}$ conversion.

\subsection{Effects of $\mathrm{H}_{2} \mathrm{O}_{2}$ concentration on $\mathrm{H}_{2} \mathrm{~S}$ conversion}

The effects of $\mathrm{H}_{2} \mathrm{O}_{2}$ in the Fenton reactor on the conversion of $\mathrm{H}_{2} \mathrm{~S}$ were studied by varying the amount of $\mathrm{H}_{2} \mathrm{O}_{2}$ in the range of $0-1400 \mu \mathrm{L}$. In the experimental series, the Fenton reactor contained $100 \mathrm{mM} \mathrm{Fe}$, and other reaction parameters were kept constant $\left(400 \mathrm{rpm}, 60 \mathrm{~min}, 25^{\circ} \mathrm{C}\right)$. The effects of the amount of $\mathrm{H}_{2} \mathrm{O}_{2}$ on the conversion of $\mathrm{H}_{2} \mathrm{~S}$ and the distribution of sulfur compounds percentage were shown in Figure 3. The comparative experiments have shown that the use of the only $\mathrm{Fe}^{2+}$ was converted to $2.6 \%$ of $\mathrm{H}_{2} \mathrm{~S}$. This result was expected since there are no free radical occurs in the solution. The results display that the increase of the $\mathrm{H}_{2} \mathrm{O}_{2}$ quantity from 0 to $800 \mu \mathrm{L}$, the $\mathrm{H}_{2} \mathrm{~S}$ conversion percentage was evaluated up to $80 \%$. The $\mathrm{H}_{2} \mathrm{~S}$ conversion percentage was decreased from $80 \%$ to $55 \%$, while their $\mathrm{H}_{2} \mathrm{O}_{2}$ quantity was increased from $800 \mu \mathrm{L}$ to $1400 \mu \mathrm{L}$. This unexpected result can be supported by the self-consumption of $\cdot \mathrm{OH}$ radical according to the following reaction [21]:

$$
\cdot \mathrm{OH}+\mathrm{H}_{2} \mathrm{O}_{2} \rightarrow \mathrm{H}_{2} \mathrm{O}+\mathrm{HO}_{2} \cdot \quad \mathrm{k}=2.7 \times 10^{7} \mathrm{M}^{-1} \mathrm{~s}^{-1}
$$

As understood from the reaction rate, the possibility of the reaction has inhibited the conversion of $\mathrm{H}_{2} \mathrm{~S}$, and also the numbers of unexpected productions were increased. 


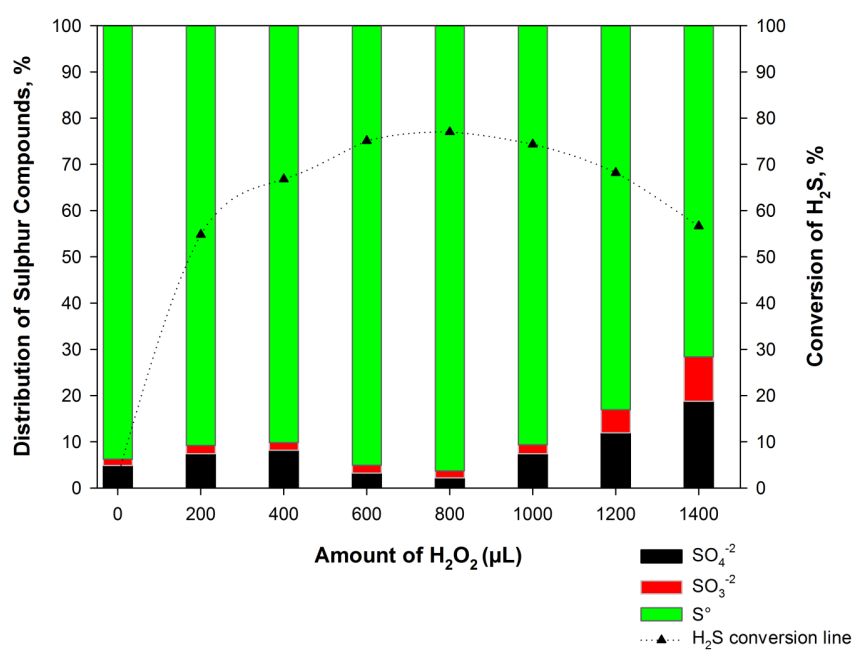

Figure 3. Changes of $\mathrm{H}_{2} \mathrm{~S}$ conversion percentage versus $\mathrm{H}_{2} \mathrm{O}_{2}$ concentration

The $\mathrm{H}_{2} \mathrm{~S}$ removal process can be carried out in two ways, $\bullet \mathrm{OH}$ radicals play a major way in the removal of $\mathrm{H}_{2} \mathrm{~S}$, and also the oxidation of $\mathrm{H}_{2} \mathrm{~S}$ by $\mathrm{H}_{2} \mathrm{O}_{2}$ can be defined as a minor way for the removal of $\mathrm{H}_{2} \mathrm{~S}$.

In industrial applications, flue gas usually includes different kinds of pollutants such as $\mathrm{SO}_{2}, \mathrm{NOx}, \mathrm{CO}, \mathrm{CO}_{2}, \mathrm{VOCs}$, etc. $[1,6]$ For this reason, the effects of combination (e.g., mixture of gases) of the industrial flue gas components on the $\mathrm{H}_{2} \mathrm{~S}$ removal mechanism should be defined and further studied in depth in future works.

\subsection{Effects of reaction time on $\mathrm{H}_{2} \mathrm{~S}$ conversion}

In this experimental series, the effect of reaction time on $\mathrm{H}_{2} \mathrm{~S}$ conversion was studied. $1000 \mathrm{ppm} \mathrm{H}_{2} \mathrm{~S}$ gas was fed into the Fenton reactor containing the mixture of $100 \mathrm{mM} \mathrm{Fe}^{+2}$ and $800 \mu \mathrm{L} \mathrm{H}_{2} \mathrm{O}_{2}$ solutions at $400 \mathrm{rpm}$ and $25^{\circ} \mathrm{C}$. Figure 4 displays the effects of reaction time on $\mathrm{H}_{2} \mathrm{~S}$ conversion percentage. Prolonging the reaction time to $600 \mathrm{~min}$ was investigated, expecting a higher conversion percentage. However, the conversion reaction was increased up to $90 \mathrm{~min}$. At that time, the highest conversion percentage was recorded as around $80 \%$. After that point, the extension of the reaction time and could not increase the conversion percentage of $\mathrm{H}_{2} \mathrm{~S}$, but unwanted species (i.e., $\mathrm{SO}_{3}{ }^{2-}, \mathrm{SO}_{4}{ }^{2-}$ ) were increased in the reactor. This phenomenon may be expressed by equation 4-6. The $\mathrm{SO}_{3}{ }^{2-}$ and $\mathrm{SO}_{4}{ }^{2-}$ species in the solution were increased with further connection $\bullet \mathrm{OH}$ radical with $\mathrm{H}_{2} \mathrm{~S}$ gas.

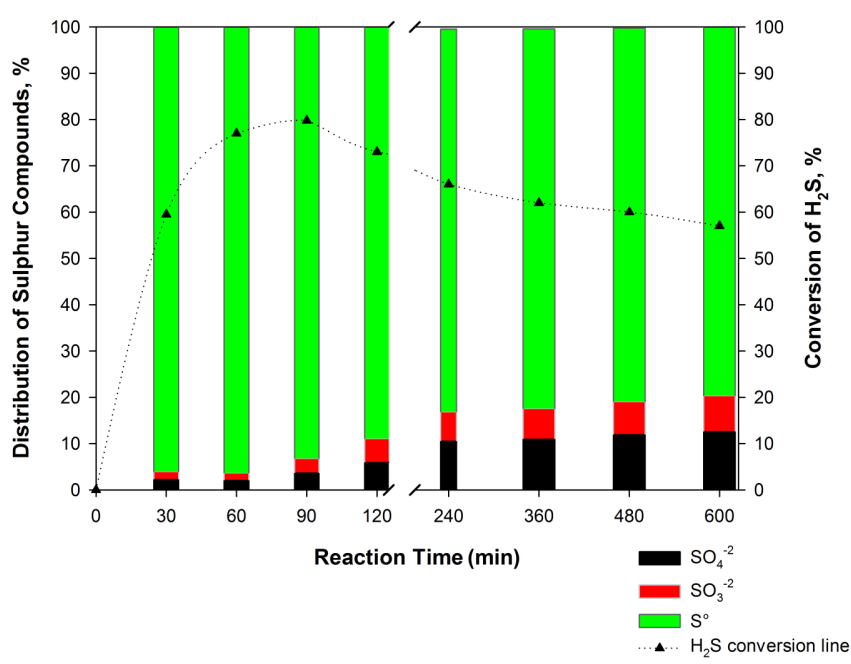

Figure 4. Changes of $\mathrm{H}_{2} \mathrm{~S}$ conversion percentage versus reaction time

After that point, the extension of the reaction time and could not increase the conversion percentage of $\mathrm{H}_{2} \mathrm{~S}$, but unwanted species (i.e., $\mathrm{SO}_{3}{ }^{2-}, \mathrm{SO}_{4}{ }^{2-}$ ) were increased in the reactor. This phenomenon may be expressed by equation 4-6. The $\mathrm{SO}_{3}{ }^{2-}$ and $\mathrm{SO}_{4}{ }^{2-}$ species in the solution were increased with further connection $\bullet \mathrm{OH}$ radical with $\mathrm{H}_{2} \mathrm{~S}$ gas.

\subsection{Effects of initial $\mathrm{H}_{2} \mathrm{~S}$ concentration on $\mathrm{H}_{2} \mathrm{~S}$ conversion}

The effect of the initial concentration of $\mathrm{H}_{2} \mathrm{~S}$ on conversion percentage was investigated. The experiments were carried out by varying the amount of $\mathrm{H}_{2} \mathrm{~S}$ gas in the range of 250 $2000 \mathrm{ppm}$. The highest reaction parameters were selected from the previous experimental results $\left(100 \mathrm{mM} \mathrm{Fe}^{+2}\right.$ and 800 $\mu \mathrm{L} \mathrm{H}_{2} \mathrm{O}_{2}$ solutions at $400 \mathrm{rpm}, 90 \mathrm{~min}$ and $25^{\circ} \mathrm{C}$ ) and they were kept constant during the experiments.

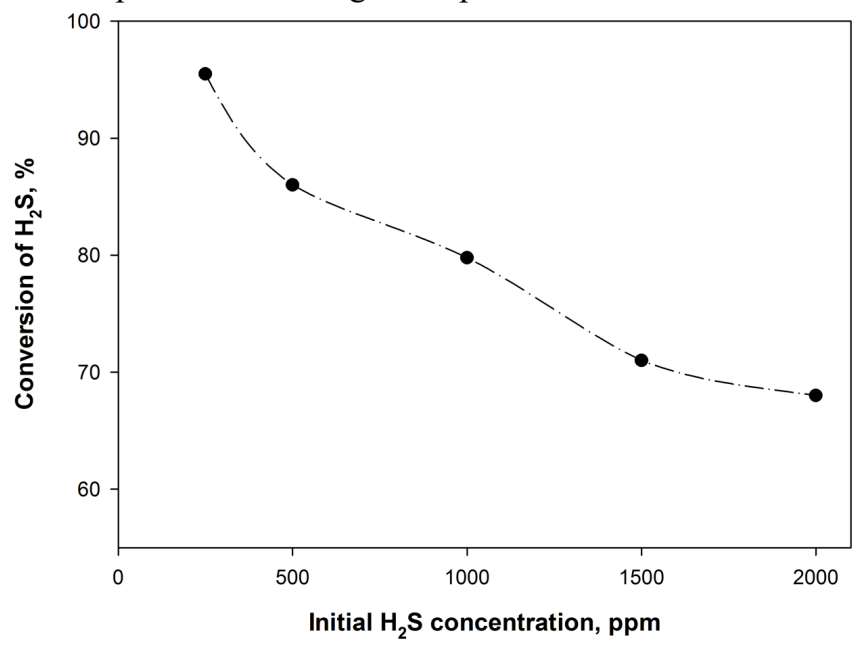

Figure 5. Changes of $\mathrm{H}_{2} \mathrm{~S}$ conversion percentage versus reaction time

According to Figure 5, the conversion percentage of $\mathrm{H}_{2} \mathrm{~S}$ decreased with increasing the amount of $\mathrm{H}_{2} \mathrm{~S}$ gas. This trend was the expected to result because the increase of the feeding 
concentration of the $\mathrm{H}_{2} \mathrm{~S}$ decreased the interaction between the $\mathrm{H}_{2} \mathrm{~S}$ molecule and reactant. This result was supported [21], who found that the $\mathrm{H}_{2} \mathrm{~S}$ conversion percentage decreased as the initial amount of $\mathrm{H}_{2} \mathrm{~S}$ increased. This experimental were provided that the $\mathrm{H}_{2} \mathrm{~S}$ conversion percentage decreased while increasing the initial $\mathrm{H}_{2} \mathrm{~S}$ concentration.

\subsection{Effects of liquid-gas ratio on $\mathrm{H}_{2} \mathrm{~S}$ conversion}

Several experiments were carried out to understand the effect of liquid-gas ratio on $\mathrm{H}_{2} \mathrm{~S}$ conversion percentage. The obtained results were presented in Figure 6.

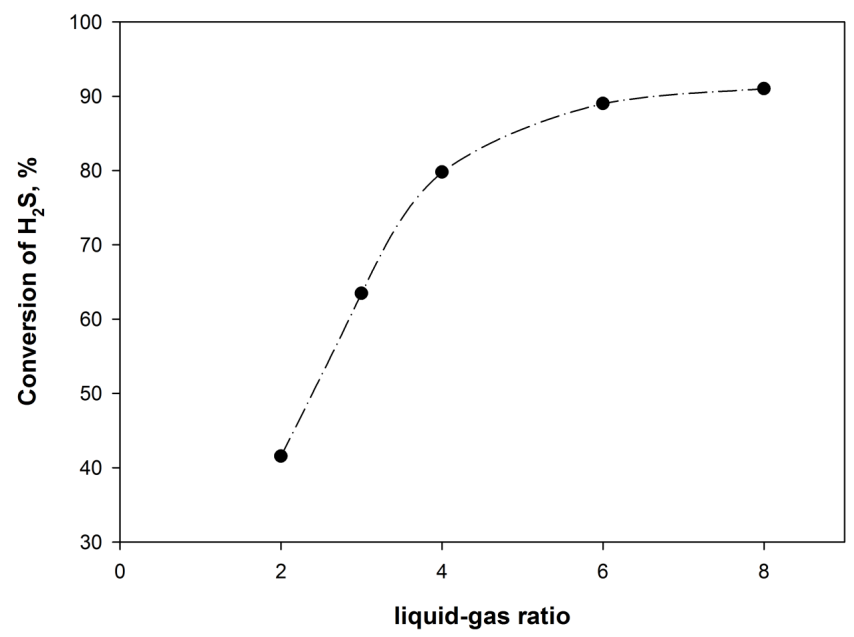

Figure 6. Changes of $\mathrm{H}_{2} \mathrm{~S}$ conversion percentage versus reaction time

It was demonstrated that the liquid-gas ratio evaluated from 2.0 to $10.0, \mathrm{H}_{2} \mathrm{~S}$ conversion percentage significantly raised from around $40 \%$ to $90 \%$. This trend can be expressed that the amount of the oxidants $\left(\mathrm{H}_{2} \mathrm{O}_{2}\right.$ and $\left.\bullet \mathrm{OH}\right)$ abounded in the reactor. In addition, the conversion process was to be more effective due to the increase of the liquid-gas ratio. Thus, the high gas-liquid ratio improves the $\mathrm{H}_{2} \mathrm{~S}$ conversion percentage. This increasing trend in our work was found to be similar [20] As a result, it was evident that an increase in liquid-gas ratio shows a significant increase in $\mathrm{H}_{2} \mathrm{~S}$ conversion. However, since more liquid-gas ratio needs more investment, the most appropriate liquid-gas ratio should be determined by considering efficiency and energy costs.

\subsection{Characterization of the reaction product}

Following the $\mathrm{H}_{2} \mathrm{~S}$ conversion process, the reaction product, which was precipitated in the reactor, was characterized using X-ray diffraction (XRD) and Scanning Electron Microscopy (SEM) with Energy Dispersive X-ray Analysis (EDX). Before XRD and SEM-EDX analysis, the solid reaction product was filtered and washed with distilled water and subsequently acetone. Afterward, the powder was dried in a vacuum desiccator at $25^{\circ} \mathrm{C}$ overnight. The $\mathrm{XRD}$ results displayed in Figure 7 shows that the precipitated powder is elemental sulfur in the reactor.

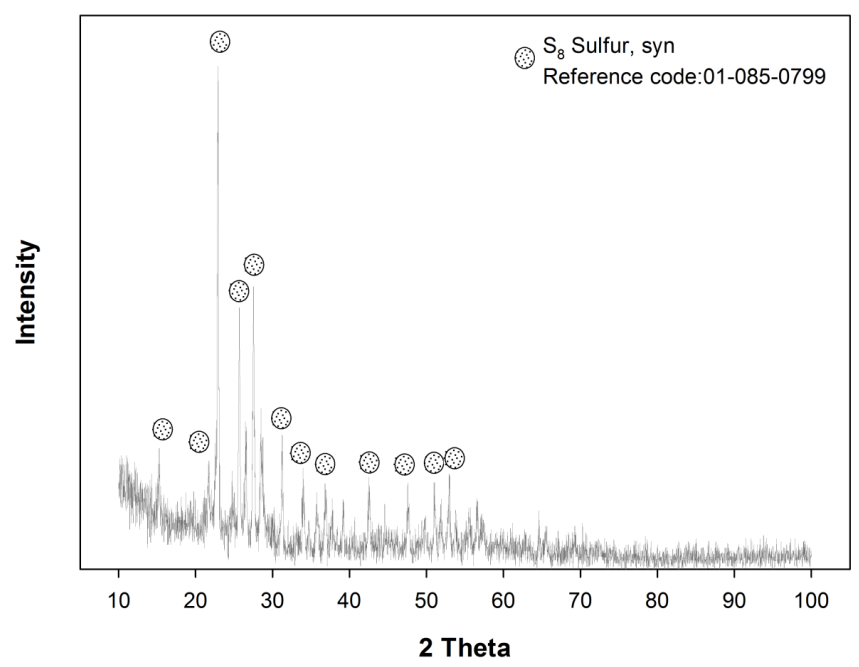

Figure 7. Changes of $\mathrm{H}_{2} \mathrm{~S}$ conversion percentage versus reaction time

To understand the morphological structure of the precipitated elemental sulfur powder was characterized by using SEMEDX. Figure 8a discloses that the sulfur particles have clearly appeared. They have an orthorhombic structure, which is the most effective form of sulphur (alpha-Sulfur). It is the conventional form stable at room temperature and atmospheric pressure. The EDX peaks (see Figure 8b) show that the powder is characteristic of the elemental sulfur phase present.

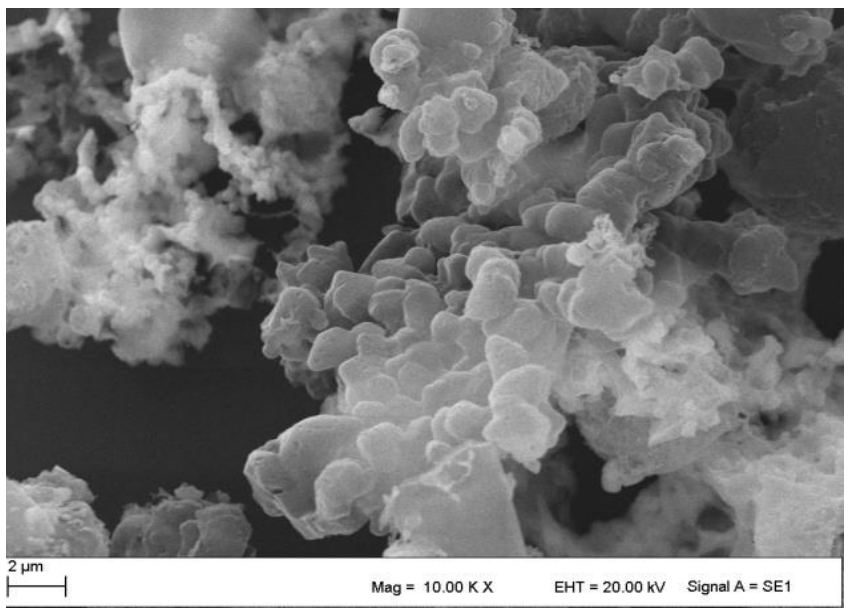

(a) 


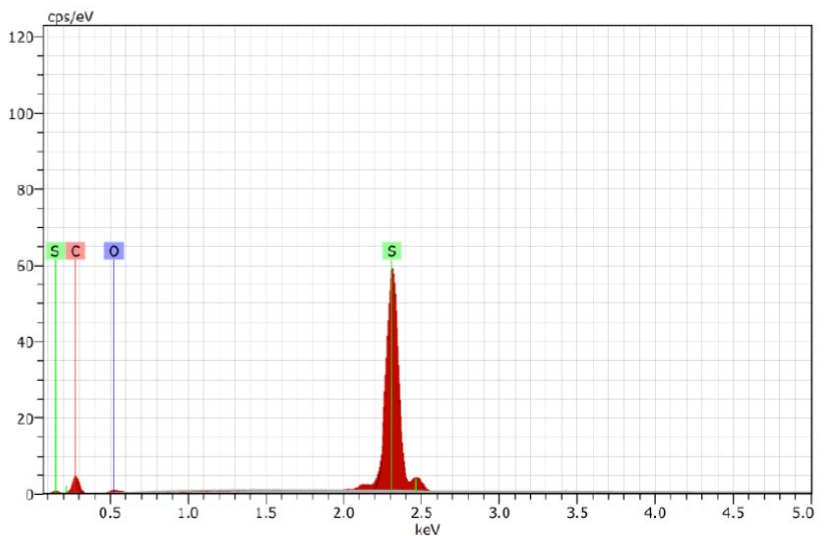

(b)

Figure 8. Changes of $\mathrm{H}_{2} \mathrm{~S}$ conversion percentage versus reaction time

The characterization result was compatible with the chemical reaction and related discussions. The precipitated elemental sulfur can be easily separated with filtration from the solution. The remaining sulfuric acid in the reactor can be concentrated by the evaporation processes or ammonium sulfate can be precipitated by adding ammonia in the reactor. Moreover, calcium sulfate can be produced by adding lime for plasterboard production, which is an essential building material. Hence, the designed process can provide zero waste liquid discharge.

\section{Conclusions}

This work covers the conversion behavior of the $\mathrm{H}_{2} \mathrm{~S}$ using Fenton regent and the determination of possible sulfur compounds in the reactor. It was found that the Fenton process facilitated the converting of $\mathrm{S}^{-2}$ to $\mathrm{S}^{\circ}$ and controlled the occurring of other species significantly. Moreover, the number of ferrous ions $\left(\mathrm{Fe}^{+2}\right)$ and hydrogen peroxide $\left(\mathrm{H}_{2} \mathrm{O}_{2}\right)$ were critical for the high conversion of $\mathrm{H}_{2} \mathrm{~S}$ in the Fenton process, with the optimal parameters of $100 \mathrm{mM} \mathrm{Fe}^{+2}, 800 \mu \mathrm{L}$ $\mathrm{H}_{2} \mathrm{O}_{2}$ at $400 \mathrm{rpm}, 90 \mathrm{~min}$, and $25^{\circ} \mathrm{C}$. Under these conditions, the conversion percentage of $\mathrm{H}_{2} \mathrm{~S}$ reached around $85 \%$. Concurrently, sulfur species such as elemental sulfur $\left(\mathrm{S}^{\circ}\right)$, sulfite ion $\left(\mathrm{SO}_{3}{ }^{2-}\right)$; and sulfate ion $\left(\mathrm{SO}_{4}{ }^{2-}\right)$ was found to $89 \%$, $2 \%$, and $9 \%$ in the reactor solution, respectively. These compounds can be further treated chemically to recover as new products. The possible conclusion results are summarized. The increase of ferrous concentration or peroxide quantity or liquid-gas ratio value can increase the conversion of $\mathrm{H}_{2} \mathrm{~S}$ percentage whereas more $\mathrm{H}_{2} \mathrm{O}_{2}$ no influenced on the conversion of $\mathrm{H}_{2} \mathrm{~S}$. The evaluating the initial $\mathrm{H}_{2} \mathrm{~S}$ concentration observed adverse effect on $\mathrm{H}_{2} \mathrm{~S}$ conversion percentage. The reaction time has a positive effect on $\mathrm{H}_{2} \mathrm{~S}$ conversion percentage up to $90 \mathrm{~min}$. The main pathway is accepted the oxidation of $\mathrm{H}_{2} \mathrm{~S}$ by radical $\bullet \mathrm{OH}$ and the oxidation and hydrolysis of $\mathrm{H}_{2} \mathrm{~S}$ by $\mathrm{H}_{2} \mathrm{O}_{2}$ are the bypath. The main products of $\mathrm{H}_{2} \mathrm{~S}$ conversion are elemental sulfur and sulphuric acid. This study lays the groundwork for future research on the processability of industrial exhaust gas such as petroleum refineries, coal-fired power plants; other power plants (e.g. burning high-sulfur residual oil and/or petcoke).

\section{Acknowledgments}

The authors gratefully acknowledge the TUBITAK (217M284) for financial support

\section{References}

[1]. Liu Y, Shi S, Wang Y. "Removal of Pollutants from Gas Streams Using Fenton (-like)-based Oxidation Systems: A Review", J Hazard Mater, (2021), 125927.

[2]. Kailasa S.K, Koduru J.R, Vikrant K, Tsang Y.F, Singhal R.K, Hussain C.M, Kim K-H. "Recent progress on solution and materials chemistry for the removal of hydrogen sulfide from various gas plants", J Mol Liq, 297, (2020), 111886.

[3]. Rubright S.L.M, Pearce L.L, Peterson J. "Environmental toxicology of hydrogen sulfide. Nitric oxide: biology and chemistry", 71, (2017), 1-5.

[4]. Lin H, Wang Y-N, Wei W, Yu Y-J. "Treatment of H 2 $\mathrm{S}$ in mine water using Fenton reagent", J China Coal Soc, 37, (2012), 1760-1764.

[5]. Liu D, Wang Q, Wu J, Liu Y. "A review of sorbents for high-temperature hydrogen sulfide removal from hot coal gas", Environmental Chemistry Letters 17, (2019), 259-276.

[6]. Lin F, Wang Z, Zhang Z, He Y, Zhu Y, Shao J, Yuan D, Chen G, Cen K. "Flue gas treatment with ozone oxidation: An overview on NOx, organic pollutants, and mercury", Chem Eng J, 382, (2020), 123030.

[7]. Wang Y, Wang Z, Liu Y. "Oxidation absorption of gaseous H2S using Fenton-like advanced oxidation systems", Energy \& Fuels 32, (2018), 11289-11295.

[8]. Liu Y, Wang Y. "Gaseous elemental mercury removal using VUV and heat coactivation of Oxone/H2O/O2 in a VUV-spraying reactor", Fuel 243, (2019), 352-361.

[9]. Wang H, Yuan B, Hao R, Zhao Y, Wang X. "A critical review on the method of simultaneous removal of multi-air-pollutant in flue gas", Chem Eng J 378, (2019), 122155.

[10]. Pagella C, De Faveri D. "H2S gas treatment by iron bioprocess", Chem Eng Sci 55, (2000), 2185-2194. 
[11]. Oyarzún P, Arancibia F, Canales C, Aroca GE. "Biofiltration of high concentration of hydrogen sulphide using Thiobacillus thioparus", Process Biochem 39, (2003), 165-170.

[12]. Deshpande A.S, Khomane R.B, Vaidya B.K, Joshi R.M, Harle A.S, Kulkarni B.D. "Sulfur nanoparticles synthesis and characterization from $\mathrm{H} 2 \mathrm{~S}$ gas, using novel biodegradable iron chelates in $\mathrm{W} / \mathrm{O}$ microemulsion", Nanoscale Research Letters 3, (2008), 221-229.

[13]. Dumont E. "H2S removal from biogas using bioreactors: a review", International Journal of Energy and Environnement 6, (2015), 479-498.

[14]. Safarzadeh-Amiri A, Bolton JR, Cater SR. "The use of iron in advanced oxidation processes" Journal of Advanced Oxidation Technologies 1, (1996), 18-26.

[15]. Cetinkaya SG, Morcali M.H, Akarsu S, Ziba C.A, Dolaz M. "Comparison of classic Fenton with ultrasound Fenton processes on industrial textile wastewater", Sustainable Environment Research 28, (2018), 165-170.

[16]. Guo R-t, Pan W-g, Zhang X-b, Ren J-x, Jin Q, Xu H-j, $\mathrm{Wu}$ J. "Removal of NO by using Fenton reagent solution in a lab-scale bubbling reactor", Fuel 90, (2011), 3295-3298.

[17]. Liu Y, Zhang J, Sheng C, Zhang Y, Zhao L. "Simultaneous removal of $\mathrm{NO}$ and $\mathrm{SO} 2$ from coal-fired flue gas by UV/H2O2 advanced oxidation process", Chem Eng J 162, (2010), 1006-1011.

[18]. Ma Y, Jin X, Hu Y, Huang Q, Wang Z. "Recovery of Hydrogen and Sulfur by Electrolysis of Ionized H2S in an Amine-Containing Organic Electrolyte with Highly Temperature-Dependent Sulfur Solubility", Energy \& Fuels 34, (2020), 7756-7762.

[19]. De Crisci AG, Moniri A, Xu Y. "Hydrogen from hydrogen sulfide: towards a more sustainable hydrogen economy", Int J Hydrogen Energy 44, (2019), 12991327.

[20]. Liu Y, Wang Y. "Removal of gaseous hydrogen sulfide by a photo-Fenton wet oxidation scrubbing system", Energy \& Fuels 33, (2019), 10812-10819.

[21]. Wang Y, Wang Z, Pan J, Liu Y. "Removal of gaseous hydrogen sulfide using Fenton reagent in a spraying reactor", Fuel 239, (2019), 70-75. 